\title{
Fostering directly observed treatment in tuberculosis: a program manager's perspective
}

\author{
Saurabh RamBihariLal Shrivastava ${ }^{\star}$, Prateek Saurabh Shrivastava, Jegadeesh Ramasamy
}

\begin{abstract}
Global Tuberculosis (TB) report (2013) has revealed that an estimated 8.6 million people developed TB of which, India accounts for almost $26 \%$ of the cases. These estimates clearly suggest that the country's efforts to achieve Millennium Development Goal 6 by 2015 have not delivered the desired output. In India, the TB prevention and control activities are supervised and implemented under the Revised National TB Control Program (RNTCP), which recognizes that implementation of a good quality Directly Observed Treatment with Short course chemotherapy (DOTS) is the first priority for TB control. Directly Observed Treatment (DOT) is the key element in DOTS strategy, in which a DOT provider insures and supports the patients in consuming their drugs throughout the course of treatment. In order to meet the country's vision to achieve universal access of TB care, the RNTCP has launched a "treatment adherence scheme" (public-private partnership scheme). Further, an evidence-based integrated strategy should be formulated for addressing the identified barriers which advocates universal administration of DOT. To conclude, DOT in RNTCP insures long-term adherence to the treatment, with right drugs in right doses, at right intervals and thus plays an indispensable role in improving the outcome indicators of the program and the quality of life in patients.

Keywords: Tuberculosis, Directly Observed Treatment (DOT), Revised National Tuberculosis Control Program (RNTCP), India

Copyright: (C) 2014 by Kerman University of Medical Sciences

Citation: Shrivastava SR, Shrivastava PS, Ramasamy J. Fostering directly observed treatment in tuberculosis: a program manager's perspective. Int J Health Policy Manag 2014; 2: 51-52. doi: 10.15171/ijhpm.2014.11
\end{abstract}

Article History:

Received: 25 October 2013

Accepted: 1 December 2013

ePublished: 5 December 2013

\section{*Correspondence to:}

Saurabh RamBihariLal Shrivastava Email: drshrishri2008@gmail.com

\section{Introduction}

Global Tuberculosis (TB) report (2013) released by the World Health Organization (WHO) has revealed that an estimated 8.6 million people developed TB and 1.3 million died from the disease in the year 2012 (1). Globally by 2012, the TB prevalence and mortality rate had been reduced by $37 \%$ and $45 \%$ since 1990 respectively (1). The coverage of anti-retroviral therapy among TB/HIV co-infected patients had gradually increased from $49 \%$ in 2011 to $57 \%$ in 2012 (1). India accounts for the maximum number of TB cases worldwide, accounting for almost $26 \%$ of the global burden (1). Similar trends have been obtained for Multi-Drug Resistant (MDR) TB as well, and again India is ranked as one among the high-burden countries (1). These estimates clearly suggest that the country's efforts to achieve Millennium Development Goal 6 by 2015 have not delivered the desired output $(1,2)$. The aim of this study is to explore the utility and advantages of Directly Observed Treatment (DOT) as an integral component of the Revised National TB Control Program (RNTCP) and to identify the potential barriers to implementation of DOT, thereby, suggesting interventions to advocate DOT across the country.

\section{The role of RNTCP}

In India, the TB prevention and control activities are supervised and implemented under the RNTCP, which recognizes that implementation of a good quality DOT with Short course chemotherapy (DOTS) is the first priority for TB control $(2,3)$. The success of DOTS strategy eventually depends on its five integral components-political commitment, good quality sputum microscopy; DOT; continuous supply of quality assured drugs, and accountability (2).

\section{DOT}

DOT is the key element in DOTS strategy, in which a DOT provider (a trained health worker/community volunteer except a family member of the patient) insures and supports the patients in consuming their drugs throughout the course of treatment (Category I= 6 months; Category II= 8 months; Category IV = 24-27 months) $(2,3)$. Considering the long duration of treatment, it has been observed that most of the patients who do not receive DOT, avoid consuming drugs once their symptoms subside $(1,2)$. This eventually facilitates drug resistance (MDR-TB or extensively drug-resistant TB) and magnifies the problem further as such patients serve as a potential source of infection to their contacts $(1,2)$. As it is not possible to predict who these patients would be, DOT makes a sincere and successful attempt to overcome the barrier of nonadherence to the treatment $(2,3)$. Studies across the world have revealed that adopting DOT in different settings has resulted in reduction in the number of cases of bacteriological failure, relapse, and acquired drug resistance; decrease in mortality rates; early detection of adverse effects, drug intolerance; and 
improvement in the quality of life of the patients and their family members (4-6). Further, contrary results in terms of poor outcome have been obtained in the absence of DOT, even when the uninterrupted supply of drugs is insured $(2,7)$.

\section{Barriers to DOT}

In an Indian set-up it has been found that almost $70 \%$ of the people avail services from the private sector (medical practitioners/laboratory/radiological investigations), owing to which most of them eventually land up in a non-DOT regimen (8). In addition, a wide range of potential factors such as strict timings of public health sector institutes; social stigma associated with the disease; prevalent myths and misconceptions; poor/ absence of networking with the private sector; geographical inaccessibility of the government healthcare institutes; lack of availability of trained healthcare providers in remote areas; deficient community ownership and participation; and poor Advocacy Communication and Social Mobilization (ACSM) activities, have not allowed the public health sector initiatives and innovations to reflect their full impact $(1-3,7,8)$.

\section{Proposed interventions}

In order to meet the country's vision to achieve the universal access of TB care, the RNTCP has launched a "treatment adherence scheme" (public-private partnership scheme) in which every DOT provider who is willing to undertake the initial home visit for address verification and defaulter retrieval for missed doses will be given an honorarium of 6.42 US dollars for every patient who has completed treatment. However, those DOT providers, who only administer treatment, will be given an honorarium of 4.01 US dollars per patient. In case of MDR-TB treatment, an honorarium of 40.15 US dollars (viz. 16.06 US dollars for intensive phase and 24.09 US dollars for continuation phase) is given for each patient completing the treatment (9). RNTCP annual report 2011 has revealed that program has involved more than 1900 Non-Government Organizations (NGOs) and more than 10,000 private practitioners in the public-private mix projects (10). In addition, an evidence-based integrated strategy should be formulated for addressing the identified barriers which advocates the universal administration of DOT. The strategy should emphasize on the preparation of a comprehensive streetwise DOT directory by health workers at the peripheral health institute level; developing partnerships with professional organizations/ non-governmental organizations; need-based execution of ACSM activities targeted to appropriate audience; sensitization sessions for private medical practitioners to adhere to the RNTCP guidelines; encouragement of healthcare providers/ community volunteers to become DOT providers; adequate counseling of the patients regarding the nature/duration/ need of adherence and completion of treatment; insuring immediate release of honorarium by the program managers/ District tuberculosis officers to acknowledge the support of
DOT providers toward the program; insuring monitoring of the DOT provider and guiding them appropriately; involvement of medical colleges-infrastructure, faculties and students; and adoption of innovative tools such as videophone to encourage administration of DOT $(1,2,5,9,11,12)$.

Ethical issues

Not applicable.

Competing interests

The authors declare that they have no competing interests.

Authors contributions

SS prepared the proposal and drafted the manuscript. PS performed review of literature and revised the manuscript critically for intellectual content. JR supervised the research process and provided overall guidance in the writing of the manuscript.

Authors affiliations

Department of Community Medicine, Shri Sathya Sai Medical College \& Research Institute, Kancheepuram, India.

\section{References}

1. World Health Organization. Global Tuberculosis Control Report 2013. Geneva: WHO; 2013.

2. TBC India. Managing the RNTCP in your area - A training course (Modules 1-4) [internet]. [cited 2013 Sep]. Available from: http:// tbcindia.nic.in/documents.html

3. TBC India. Guidelines for PMDT in India, 2012 [internet]. [cited 2013 Sep]. Available from: http://tbcindia.nic.in/documents.html

4. Pasipanodya JG, Gumbo T. A meta-analysis of self-administered vs directly observed therapy effect on microbiologic failure, relapse, and acquired drug resistance in tuberculosis patients. Clin Infect Dis 2013; 57: 21-31.

5. Seaworth BJ, Armitige LY, Griffith DE. First do no harm--adverse events, drug intolerance, and hepatotoxicity: how can we not justify directly observed therapy for treating tuberculosis? Clin Infect Dis 2013; 57: 1063-4.

6. Chung WS, Li CR. Can DOTS improve quality of life among patients with pulmonary tuberculosis? Int J Tuberc Lung Dis 2013; 17: 425-6.

7. Mkopi A, Range N, Lwilla F, Egwaga S, Schulze A, Geubbels E, et al. Adherence to tuberculosis therapy among patients receiving home-based directly observed treatment: evidence from the United Republic of Tanzania. PLoS One 2012; 7: e51828.

8. Ministry of Health and Family Welfare. National Family Health Survey (NFHS-3); 2005-06 [internet]. [cited 2013 Sep]. Available from: http://www.measuredhs.com/pubs/pdf/SR128/SR128.pdf

9. TBC India. Managing the RNTCP in your area - A training course (Modules 5-9) [internet]. [cited 2013 Sep]. Available from: http:// tbcindia.nic.in/documents.html

10. TBC India. RNTCP Annual Report 2011 [internet]. [cited 2013 Dec]. Available from: http://tbcindia.nic.in/documents.html

11. Sharma SK, Mohan A, Chauhan LS, Narain JP, Kumar P, Behera $\mathrm{D}$, et al. Contribution of medical colleges to tuberculosis control in India under the Revised National Tuberculosis Control Programme (RNTCP): lessons learnt \& challenges ahead. Indian J Med Res 2013; 137: 283-94.

12. Gassanov MA, Feldman LJ, Sebastian A, Kraguljac MJ, Rea E, Yaffe B. The use of videophone for directly observed therapy for the treatment of tuberculosis. Can J Public Health 2013; 104: e272. 